\title{
The relational dynamics of hegemonic masculinity among South African men and women in the context of HIV
}

\section{Erin Stern \& Rosemarie Buikema}

To cite this article: Erin Stern \& Rosemarie Buikema (2013) The relational dynamics of hegemonic masculinity among South African men and women in the context of HIV, Culture, Health \& Sexuality, 15:9, 1040-1054, DOI: 10.1080/13691058.2013.805817

To link to this article: https://doi.org/10.1080/13691058.2013.805817

曲 Published online: 27 Jun 2013.

Submit your article to this journal $₫$

Џلll Article views: 388

Q View related articles $\longleftarrow$

Citing articles: 30 View citing articles 4 


\title{
The relational dynamics of hegemonic masculinity among South African men and women in the context of HIV
}

\author{
Erin Stern ${ }^{\mathrm{a} *}$ and Rosemarie Buikema ${ }^{\mathrm{b}}$ \\ ${ }^{a}$ Women's Health Research Unit, School of Public Health, University of Cape Town, Cape Town, \\ South Africa; ${ }^{b}$ Graduate Gender Programme, Department of Media and Cultural Studies, Utrecht \\ University, Utrecht, The Netherlands
}

(Received 6 December 2012; final version received 13 May 2013)

\begin{abstract}
In South Africa, the frequent positioning of men's sexual behaviours as a prime driver of the HIV epidemic has generated much interest in men's sexuality. However, the relational nature of dominant male norms that exacerbate the risk of HIV transmission is inadequately understood. This study used sexual biographies to explore how men and women negotiate gendered norms and how this affects their sexual and reproductive health (SRH). A total of 50 sexual-history interviews and 10 focus group discussions were conducted with men, and 25 sexual-history interviews with women, with participants sampled from three age categories (ages 18-24, 25-55 and 55 + years), a range of cultural and racial backgrounds and urban and rural sites across five provinces in South Africa. The narratives illustrate that men and women's SRH is largely dependent on the type and quality of their relationships. Men's sexuality was regularly depicted as being detached from intimacy and uncontrollable, which was premised as being opposite from and/or superior to women's sexuality and could justify men's high-risk sexual behaviours. Yet many participants also supported gender equitable relationships and endorsed accountable and healthy SRH behaviours. The narratives reveal that HIV-risky dominant male norms should be addressed relationally for the sake of better SRH outcomes.
\end{abstract}

Keywords: Masculinity; relationships; HIV/AIDS; sexual health; South Africa

\section{Introduction}

In the past two decades, there has been an explosive growth of interest and attempts to engage South African men in HIV prevention and care. Efforts to involve men stem from the widespread documentation that women often hold less power in relationships in terms of sexual decision-making (Shefer et al. 2007; Campbell et al. 2008). Moreover, women may experience mistreatment, including abuse or abandonment, for initiating safer-sex practices (O'Sullivan et al. 2006; Reddy and Dunne 2007). Various studies have demonstrated how hegemonic masculine norms that promote men's sexual entitlement to women can result in men's higher-risk sexual behaviour, violent behaviour and/or the pursuit of multiple partners (Wood and Jewkes 2001; Hunter 2005; Jewkes and Morrell 2010). Cultural norms typically dictate that men should provide for women financially, yet transactional sex has been shown to be associated with greater power given to men to determine the type of sex, including whether to use condoms (Jewkes et al. 2012b; Shefer, Cloves, and Vergnani 2012). Furthermore, South African men have been shown to be more reluctant than women to test for HIV and less likely to access antiretroviral treatment (ART) (Pettifor et al. 2005; Peacock et al. 2009).

*Corresponding author. Email: erin.stern@uct.ac.za 
Society's routine depiction of men as invulnerable, and a general perception of sexual and reproductive health (SRH) clinics as being a woman's domain, are said to play a role in hindering men from seeking SRH care (Dwadwa-Henda et al. 2010). As a result is now widely understood that HIV-prevention efforts must involve and target men to be most effective.

The concept of hegemonic masculinity refers to a set of social norms that men are encouraged to subscribe to in order to be legitimised and recognised, which has to constantly be aspired to rather than being a given quality (Connell 1995; Shefer et al. 2007). These standards not only maintain men's power over women, but also produce hierarchies between men, as men who do not endorse dominant norms of masculinity are often marginalised by both genders (Connell 1995; Jewkes and Morrell 2010). The framework of hegemonic masculinities has been widely drawn upon in HIV-related research to support the recognition that HIV-prevention efforts must promote a shift in masculine norms linked to HIV risk rather than focus primarily on individual behaviour change. However, men who feel disempowered by, or who challenge, gendered norms, are often neglected in HIV-research and prevention efforts. Homogenising men's experiences fails to appreciate that not all men hold unbridled power, since issues of socioeconomic class, race and sexuality can oppress both men and women (Peacock et al. 2009). Particularly in the African context, hegemony is often linked with a portrayal of 'bad men' (Morrell, Jewkes, and Lindegger 2012), which can contribute to essentialist notions of 'African masculinity' and sexuality. Yet, various studies suggest that men hold multiple and even conflicting social identities simultaneously such as in a particular social context (Cornwall 1997) or in a certain social grouping (Frosh, Phoenix, and Pattman 2002). Some research has recognised shifting masculinities in relation to the HIV epidemic (cf. Hunter 2010; Dworkin et al. 2013). For instance, Robins (2008) documented 'responsible masculinities' wherein HIV-positive men in a Cape Town township were given a safe space to discuss how HIV, unemployment and poverty affected their identities as men. The support groups contributed to higher levels of ART adherence and HIV-status disclosure and also resulted in the men's greater commitment towards family and community.

Reformulations of the concept of hegemonic masculinity should not only more adequately consider diverse forms of masculinity, but should also be more attentive to the production and construction of masculine norms by women (Connell and Messerschmidt 2005). Brod (1994, as cited in Connell and Messerschmidt 2005) observed that 'there is a tendency in men's studies to presume separate spheres as if women were not a relevant part of the analysis and to analyse masculinities by looking only at men and relations among men' (837). Research on the topic of masculinity rarely involves women and, if it does, their voices are often neglected in the analysis. For instance, Talbot and Quayle (2012) reviewed 140 evidence-based studies published between 1999 and 2007 in the journal Men and Masculinities. Of the studies that relied on archival data, about $77 \%$ had analysed articles that were predominantly about men. Of 84 published studies that used interview data, $69 \%$ had interviewed only men. While other articles had included female participants, the insights of women were regularly underrepresented in the published study. Moreover, the HIV and AIDS literature regularly depicts young women as victims and men as perpetrators, without acknowledging 'resistances, alternative discourses and contradictions in dominant discourses on heterosexual practices' (Shefer and Foster 2009, 270). In such ways, studies of masculinity have been criticised for reinforcing essentialist divisions between men and women and 're-excluding' women (Hearn 2004). 
Some South African studies have emphasised women's participation in the production and maintenance of hegemonic male norms, such as Talbot and Quayle's (2012) study with middle-class women at a university. The women identified forms of masculine hegemony (for example, being aggressive) as problematic in the contexts of work and school, yet they valued these traits in a romantic context, perhaps because 'the stages of being in love are so tied up with hegemonic masculinity and submissive femininity' (275). Jewkes and Morrell's (2012) study with women in the rural Eastern Cape revealed a dominant femininity that negotiated respect, independence and non-violence within sexual relationships, while still maintaining culturally appropriate hierarchies between men and women deemed to be culturally acceptable. In South Africa, dominant cultural scripts, or 'statements that prescribe recipes for living' (Leclerc-Madlala 2009, 108), hold that male sexuality is perceived as uncontrollable and that men are biologically programmed to need sex regularly and with more than one woman. Such cultural scripts also promote norms of womanhood to understand and tolerate a man's infidelity in relationships as inevitable. Other research has challenged the victim/perpetrator binary in sexual relationships by revealing the desire of women to have unprotected sex in order to meet their material needs (Susser and Stein 2000; O'Sullivan et al. 2006) or to procreate (Wood and Jewkes 2006). However, as Mfecane (2013) argues, women's agency around sexual decision-making must be understood within the gendered power inequalities in South Africa. Women's aspirations for motherhood and to gain financially may also reflect societal pressure on women to prove their fertility and the limited economic opportunities available to women.

Assessing how men and women condone and challenge hegemonic gender norms in relationships is necessary to develop more situated and nuanced understandings of male sexual risk and agency. This paper uses a narrative approach to investigate the relational nature of hegemonic masculinity in terms of the ways South African men and women endorse gendered norms in and through their relationships and how this impacts on their SRH practices. A narrative approach is beneficial for probing the diversity and fluidity among men and women's individual experiences, while still recognising the context and normative gendered repertories that influence their SRH behaviours. Narratives also appreciate how individuals make sense of their experiences and can uncover the range of meaning and expectation given to relationships.

\section{Methods}

\section{Participants}

Sexual-life-history interviews were conducted with 50 men and 25 women at six sites across five provinces in South Africa (Eastern Cape [2 sites], Western Cape, KwaZuluNatal, Mpumalanga and Gauteng). At each site, interviews were conducted with men and women in three age categories (ages 18-24, 25-55 and 55+ years) and from the various racial and cultural groups to assess variations among individuals and changes within one's lifespan. Efforts were made to recruit heterosexual male and female participants to appreciate how norms of masculinity are produced in and through heterosexual relationships. By comparing men and women's sexual-history narratives, differences in reported gender norms and sexual behaviours could be assessed. To triangulate the data, 10 focus-group discussions (FGDs) (two in each of the provinces) were also conducted with 8-10 men per group. Sites were purposively chosen to enhance diverse cultural, economic and social representation of participants. To ensure confidentiality of the participants, any identifying information was removed and all names have been changed. 


\section{Recruitment}

An information sheet explaining the project's purpose and the benefits and risks of participating was distributed by the first author to a community contact person who was well acquainted with each study site. The contact person prepared a random list of people who fit the selection criteria in terms of the age, racial and gender categories and notified people who fit the requirements. Community contacts were developed through the non-governmental organisations Sonke Gender Justice (Mpumalanga and Western Cape), Centre of AIDS Development, Research and Evaluation (CADRE) (Western Cape, Eastern Cape, Gauteng and KwaZulu-Natal) and through contacts developed by the first author after a year spent working with TransCape (Eastern Cape).

Community contacts could establish rapport with the interview participants, which was important given the sensitive and personal nature of the topic. The community contact was given R100 (approximately US\$11.25) as a stipend for each participant recruited.

\section{Procedure}

Ethical approval was granted by the Human Research Ethics Committee of the University of Cape Town Health Sciences Faculty. Participants signed informed consent for participation in an interview or FGD and were given R100 (approximately US\$11.25) as a token of appreciation for participation. Data collection occurred between August 2010 and December 2011. On average, interviews lasted one-and-a-half hours and FGDs lasted two hours. Interviews and FGDs were conducted in the language preferred by the participants and participants who were paired with same-sex interviewers due to the private and sensitive nature of the topic, and in order to appreciate how men and women perform to constructions of masculinity and femininity in dialogue with members of the same sex. Interviews with women that could be conducted in English were mostly conducted by the first author. ${ }^{1}$ Among the remaining participants, experienced researchers were hired to conduct the interviews. The topic guide was developed by the first author as well as four other researchers from CADRE. Participants were first asked to account for their early knowledge of sex and sexual experimentation and then discuss their range of sexual relationships and experiences through to adulthood. Engagement with the risk of a sexually transmitted infection (STI), including HIV, as well as norms of masculinity, were explored in relation to the men and women's experiences of male sexuality. Interview questions and probes were designed to elicit narratives that would reveal attitudes of and engagement with gender norms such as the questions: 'Do men and women have different thoughts about the connection between love and sex?' 'What makes you say this?' 'Tell me stories that illustrate what you mean?' Notes of the interviewer's impressions were taken immediately after each interview and used in the analysis.

\section{Data analysis}

To analyse the data, thematic networks were created to reveal prominent themes in the data with the use of NVivo qualitative data management software to manage the thematic analysis (cf. Attride-Stirling 2001). After the first author and four researchers from CADRE had immersed themselves in the data to identify patterns, a preliminary coding structure for analysing the data systematically was established. In this process, the researchers analysed the responses to the research questions and mapped out the most 
important constructs that shaped the respondent's responses. The researchers deliberately worked to bracket assumptions and to build an inductive understanding to ensure identification of themes that had not been anticipated during background research. The transcripts were coded to identify recurring themes by sorting key findings that could be ascribed to each basic code. Once all the text segments had been given basic codes, the codes were categorised into basic themes by placing similar codes together. Additional basic themes were created during this process, which required continually going back to the transcripts to select relevant latent meaning in the text. Coding was regularly discussed between the first author and CADRE researchers to obtain conceptual alignment on existing and emerging codes.

\section{Findings and discussion}

The participants' narratives suggest that HIV-prevention behaviour is strongly determined by the type and quality of one's sexual relationships, which attests to the importance of studying men's HIV-risky behaviours from a relational perspective. Findings will be presented along the three major types of relationships identified: established relationships, casual relationships and multiple concurrent relationships.

\section{Established relationships}

\section{Characteristics of established relationships}

Both men and women asserted the value of established relationships for their emotional benefits. In order to be in an established relationship, it was generally agreed that one must be willing to make compromises and put aside one's own needs:

I can get into a relationship with my principles and my rules and my regulations, but there is somebody else involved, it is not just about me; and if I want it to work, then it must be about us, because we are in this thing together. (Duane, coloured male, urban, age group $18-25)$

One man expressed his desire for having an established relationship but felt concerned that he was not prepared for the effort it would involve:

The minute I feel challenged in the relationship then I'll run to somebody else to get validation from them, because ... it's simpler. I want to have just one relationship now; I'm just concerned about whether I can or not, really. (Andrew, white male, urban, age group 25-55)

The compatibility of partners was said to be critical for forming an established relationship because of the level of effort required. There was some consensus that in the changing social context in South Africa, women have increasing agency around what to expect from a partner:

In olden days you didn't say 'No I don't want him.' You have to say 'Yes, I love you.' Even though you don't want to have a man, you need to say yes. So nowadays if I don't want that boy, I say 'No, I don't want and I don't like you,' you see? It's different than olden days. (Bongekile, tsonga female, urban, age group 18-24)

Timing was also said to be critical to the formation of an established relationship, which requires significant work and readiness:

There's no point in me getting into a relationship if it's going to be for two months ... or three months or six months. But if I'm going to get involved with someone, I must know that there are securities in place, otherwise I just don't bother. (Nial, white male, urban, age group $18-24)$ 
Both men and women regularly defined established relationships by emotional intimacy, with kissing and cuddling being an integral part of sexual expression. Sex was regularly said to be more meaningful and rewarding in such relationships:

The sex was good. It wasn't just sex, it was making love. After sex you cuddle and talk ... that got me attached emotionally. With the one-night stands, you don't do that, you don't cuddle. You just $f * * k$, and when you're done, you look the other way. (Bongani, xhosa male, urban, age group 25-55)

Some women expressed surprise when through their relationships, they discovered men who preferred emotional and physical intimacy, which contradicted their dominant understandings of masculine sexuality. Open communication about relationship needs and desires, including sexual desires, was also considered to be an important and valued characteristic of established relationships. Although, for many women, hegemonic norms of femininity hindered sexual openness with their partners:

Women, even if they want to have sex, they are shy to tell a guy that I am having these feelings, these desires today. We grew up in an environment where men must start everything. But I think now it is going to change. (Akantse, sotho female, urban, age group 25-55)

It was predominantly older women who reported more openess about their sexual desires in relationships, a finding in congruence with other studies (cf. Shefer and Foster 2007):

Because you know when you get before that, you are more trying to please the man or whatever it is. When you get to our age, it's a partnership. ... So I'm not pleasing you, you're not pleasing me, we're here to please one another. (Faranah, coloured female, urban, age group 25-55)

Another regularly mentioned and valued characteristic of established relationships was monogamy and commitment. There was general agreement that partners need to satisfy each other sexually to prevent a partner's infidelity:

If you are not open to talk about sexual things, you will keep on not satisfying your partner.

If there is no harmony in the bedroom, no matter the amount of money you are going to make won't keep your wife from straying. (Barry, coloured male, urban, age group 25-55)

Such narratives support the literature documenting male sexuality as a source of various insecurities, which contradicts the conceptualisation of men as all powerful and in control of sexual encounters (Schneider, Cockcroft, and Hook 2008). Given the expectation of monogamy in established relationships, both men and women expressed disappointment and/or pain as a result of infidelity in such relationships:

The serious relationship is so draining to tell you the truth. With the casual one even cheating is ok with me, it's his own life. With the serious relationship, if he cheats on me I am so emotionally drained, I sleep with a broken heart, I cry myself to sleep. (Gabby, tsonga female, urban, age group 25-55)

In many cases, discovering a partner's infidelity propelled participants to end an established relationship.

\section{Sexual behaviours in established relationships}

Various participants discussed how they preferred established relationships not only because of the benefit of emotional and physical intimacy, but because they were perceived as safer in terms of HIV risk:

I learned that if you had one partner ... you can escape this thing of HIV and AIDS, because if you are going around sleeping around with any Tom, Dick and Harry, you are going to get caught up in it. (Khulani, zulu male, urban, age group 25-55) 
The notion of unprotected sex was very popular among the participants, although it was generally agreed that this would be more appropriate in the context of established relationships where there is 'trust'. Condom use was also routinely described as neglected in established relationships for detracting from sexual satisfaction, which was often asserted to be a critical component of such relationships. Condom use appeared to be inconsistent with the established relationship ideals of intimacy and fidelity, an observation that is well documented in the literature (e.g. Cusick and Rhodes 2000; Harrison 2008; Corbett et al. 2009). Some participants remarked that trust with a partner could develop 'too quickly', even within one week. Men in particular spoke of assessing a woman based on her attractiveness, hygiene or her reputation as denoting that she was 'healthy', meaning free of HIV infection:

I was just looking. This one is fat, so she is healthy. Whereas this one, if she is too skinny, maybe she is sick [HIV-positive]. (Khensani, tsonga male, rural, age group 25-55)

Alternatively, some women discussed concern that attractive men were less likely to be monogamous, which may reflect hegemonic norms that men are unable to resist sexual temptation:

I looked at him and was like, 'Oh my god, this guy is handsome and I know he's not attracting me only. So he might have attracted someone and then no way, in case maybe something else happens.' Cause sometimes you engage in sex unexpectedly, so I told him we need to go [for an HIV test]. He was so open. (Bina, sotho female, age group 25-55)

As reflected in this narrative, many couples who tested for HIV together reported that they did so because of the encouragement and/or initiation by the female partner. Nonetheless, the majority of participants discussed establishing trust in relationships without testing for HIV. Repetitive HIV-testing among couples was also reportedly rare, which was said to conflict with the reported value of fidelity in established relationships. Among participants who reported regular condom use in established relationships, the most commonly given motivator for this was to prevent pregnancy.

\section{Casual relationships}

\section{Characteristics of casual relationships}

Men discussed having a higher number of casual sexual encounters on average than the women, although there may be a discrepancy between the participants' responses and their actual behaviour due to socialised gender expectations. Several participants mentioned how having casual relationships are a phase that many young people go through, eventually progressing to commitment in established relationships with age: 'It's a stage that people have to go through. It doesn't last long as people grow up' (Dineo, pedi female, urban, age group 25-55). Some participants discussed how they were much less particular about what they looked for in casual partners as opposed to seeking compatibility in an established relationship. One man, Xolani, said, 'You don't check, as long as it's a woman it's fine' (zulu male, urban, age group 25-55). Both men and women generally agreed that casual relationships do not involve long-term plans:

It's something that you don't feel anything, you just go because at that time you don't want to be lonely, so you just go with the flow. You don't know where it's going to end, and if it ended now you wouldn't even care. (Rapula, Sotho male, urban, age group 25-55)

There was often less emotional intensity and forms of intimacy accompanying casual sexual relationships. One man used hostile language to denounce how women were prone 
to expecting similar levels of affection in casual relationships as in established relationships:

There is no way I will respect you for that. I don't know how many men you have been sleeping with, and now you want to hold me, you want to explain stories as if we are in love, and I mean there was only one objective and that was only to $\mathrm{f} * * \mathrm{k}$. They forget that it was just a one-night stand. (Ndumiso, zulu male, urban, age group 18-24)

Many participants asserted that men had uncontrollable physical needs and possessed an ability to disassociate sex and intimacy, which motivated men's regular involvement in casual sex. One woman explained:

They claim they want to experience. If sometimes he's dating a skinny girlfriend and then he sees someone curvy. And he thinks, 'Oh my god, I can go see what it's like to have sex with a curvy one.' So easy. They are not so attached as us women. Men can have sex with you, the following day they forget about you. (Bina, sotho female, urban, age group 25-55)

Yet several participants also discussed how it was becoming more acceptable and prevalent for women to openly seek casual relationships where love and sex was separated:

In olden days if I want sex with a man they gonna call me a bitch. But nowadays it's changed.

It's because it's the new South Africa, maybe. (Portia, swati female, urban, age group 25-55)

Despite these perceived social changes, many male participants discussed how they often lie about their intentions or use strategies such as expressing false love to initiate casual sex, since dominant conceptions of femininity expect women to refuse men's casual sexual advances:

You have to lie to women to get what you want. If you can practice the truth, you will never have sex. If I see you for the first time and I say to you, 'After these drinks, can we go and have sex?' - you will think I am disrespecting you, I am making you out to be a bitch and a prostitute and whatever; so I have to lie and say 'I love you'. (Sipho, zulu male, urban, age group 18-24)

Many participants, in congruence with other studies, discussed how casual relationships were commonly formed after the consumption of alcohol (cf. Pettifor et al. 2005). One participant (Yongama, xhosa male, urban, age group $55+$ ) described how men will buy alcohol for women with the intention of getting sex and if a woman refuses sex after a man has bought her alcohol, she could be subject to violence. Many of the men also stated that money is central to create opportunities to have casual relationships with women:

They will hook me up with someone, because at that time, 20 or 30 Rand was enough to spoil a girl a little bit. (Atile, sotho male, urban, age group 25-55)

Such narratives confirm the findings of other studies that have identified money as a primary motivator for women to engage in casual relationships (Campbell and MacPhail 2002; Jewkes and Morrell 2012). Relationships involving such transactions were said to be particularly prominent among relationships with a large age difference between the partners:

The rich guys $f * * k$ up the world for the rest of us. They date younger girls because they do have money. If you flash money, all girls will come. Predominantly you will find young girls are getting pregnant regardless of the education they got at school about sexual diseases.

(Tembe, swati male, urban FGD, age group 25-55)

As alluded to in this man's comments, research has documented how transactional and/or age disparate relationships are often characterised by unprotected sex, where the older provider/partner has more sexual decision-making power (Jewkes et al. 2012a). 


\section{Sexual behaviours in casual relationships}

The participants discussed how they are more likely and in some cases vigilant to use condoms in casual sexual encounters because of the greater SRH risks in such encounters. For some men, it was the fear of fathering a child with a woman they were not in love with or committed to that encouraged their consistent condom use:

So you had these opportunities for casual sex, turned it down, and your main motivation was fear of consequences that come with casual sex. Like you have sex with a chick once, you think it's casual, meanwhile this chick wakes up in the morning and tells you that she's pregnant, and then you find yourself in a world of shit. (Nial, white male, urban, age group $18-24)$

Although the majority of participants asserted the importance of practising safer sex in casual relationships, condoms were not always used consistently. Several participants, particularly men, perceived condom use to be less likely if they have consumed too much alcohol. For some, it was simply spontaneity, or 'the heat of the moment', in casual encounters that hindered condom use. Several men discussed their reluctance to initiate condom use in casual sexual encounters and they suggested that women should always carry condoms and initiate condom use, which respects the agency of women to make sexual decisions. However, the expressed capability of women to initiate condom use may also reflect the fact that "current contraceptive arrangements unfairly burden women with most of the responsibility for and negative effects (e.g. health, social and financial) of contraception' (Campo-Engelstein 2013, 293).

\section{Multiple concurrent partnerships}

\section{Characteristics of multiple concurrent partnerships}

Some participants discussed their experiences of multiple concurrent partnerships, meaning consistent sexual relationships with two or more partners over a regular period of time. More men than women openly spoke of engaging in multiple concurrent partnerships, although the participants largely agreed that there was greater disapproval of concurrency for women, which may have discouraged women's reporting of such relationships. Several participants highlighted the cultural pressures on African men in particular to have concurrent partners to gain status. One participant said that he might have been monogamous, if not for such pressure:

But we grew up in the township where there was this peer pressure [laughs], so in order to show off that you are ... it's nature. It's us as African men. (Sipho, zulu male, urban, age group 25-55)

Alternatively, cultural standards were generally said to condemn women having multiple partners:

You know cultural things. They will tell you men can have two wives. But women can't have two husbands: that's impossible in our culture. (Akantse, sotho female, urban, age group 25-55)

It was also stated that seeking multiple partners was especially important for men who suffered from low self-esteem, as having multiple partners could enhance a man's status. Indeed, both male and female participants discussed the negative and emasculating image men may have if they have only one or no sexual partners:

There are lots of bad words which are attached to a person who had fewer girlfriends ... they call you she-man and stuff like that. It's more embarrassing. (Khulani, zulu male, urban, age group 25-55) 
In one narrative, a man referred to his side partners as 'stolen', who have certain conditions imposed on them that the main partner is not subject to:

The main one is also allowed to go to your house at any time and see your family members. The stolen one is not welcome at your house. She is not to be known. You put rules on the stolen one, which is also the difference. Like don't call me, I'll call you. She knows, and you have told her you have a girlfriend. She knows we will be stealing each other. (Siyanda, xhosa male, rural FGD, age group 25-55)

Another term regularly used to describe side partners was khwapheni, a Xhosa word used to refer to a sexual partner who is kept hidden. ${ }^{2}$ These terms both suggest that side partners were meant to be kept secret from the main partner. For women who were involved in multiple concurrent partnerships, the most common reason to engage in such partnerships was an economic need or desire, as documented in the literature (cf. Leclerc-Madlala 2009; Jewkes et al. 2012b):

You find too you might love this guy a lot, but he does not have money, he does not take you out a lot. And you find the other guy can take you anywhere, anywhere, but the love is not that much. The intimacy and connection is not there. (Bina, sotho female, urban, age group 25-55)

Both men and women expressed the view that concurrent sexual relationships were more likely to occur if one partner is not physically or emotionally satisfied in their relationship, as noted in other studies (cf. Mah and Maughan-Brown 2013). Several participants reported that when their established partner did not want to have sex, it could imply that their partner was unsatisfied and/or having an affair. Such insecurity and mistrust hindered commitment to one partner for some participants:

I think it won't work for me, because I'm just thinking in terms of loving one person but what if that person leaves you one day? (Kefentse, tswana male, urban, age group $18-24)$

\section{Sexual behaviours in multiple concurrent partnerships}

For the most part, sexual behaviour with side partners imitated that of casual relationships, where there was more evidence of regular condom use. As one man said:

There is a difference between khawpeni and my wife. Because my wife, I have had some blood tests with her and then I trust her too much. I know she is faithful even though myself I am not faithful. But with khawpeni I don't give them love. I always use condoms with them. (Daegan, tsonga male, urban FGD, age group 25-55)

Indeed, many men expressed how 'condomising' with side partners was particularly important in multiple relationships in order to protect the main partner from HIV infection:

I don't take a chance with my stolen ones. Only with the mother of my child who I love. I don't want to infect her with these diseases. People mustn't tell my kids, 'Your parents died because your dad infected your mother with AIDS, because of your stupid father'. (Thando, xhosa male, urban, age group 25-55)

Nonetheless, a few women lamented how female 'main partners', particularly married women, were at pronounced risk of STI infection if their partner had multiple concurrent partnerships, since sex in marriage was less likely to be protected:

And these are all married women, not single women. That's the sad thing. A very good married friend of mine also experienced it, she had to go and get a test done and get an antibiotic to clear herself. (Eleanor, coloured female, urban, age group 25-55) 


\section{Discussion}

Using the participants' sexual biographies exposed variations in the norms and subjective meanings of different types (established, casual, etc.) of sexual relationships. Men's sexuality was regularly premised as being detached from intimacy and uncontrollable, which was positioned as opposite and/or superior to women's sexuality. Such notions could be used to justify men's high-risk sexual behaviours, including reluctance to use condoms and pursuit of multiple concurrent partnerships. Yet the narratives also support the notion that gender norms in sexual relationships are changing in South Africa (O'Sullivan et al. 2006; Dworkin et al. 2011) and that it is simplistic to assume a dichotomy in relationships, wherein men have absolute sexual decision-making power and there is no acknowledgement of women's agency. It is important to note, however, that there may be a discrepancy between perspectives about gender norms and values, as revealed through the narratives and the lived experiences of men and women. For instance, Pettifor et al. (2013) found that young women in Johannesburg valued equality and respect in sexual relationships where they had some decision-making power, yet only one-third of the women were in a relationship with no abuse or infidelity and where condoms were used consistently. Dworkin et al. (2013) found that men who participated in the 'One Man Can' campaign, which provides a space for critical reflection on masculinity and gender equality, had better awareness of women's rights and embraced more gender-equitable norms in their relationships, including respect, open communication, equal sexual decision-making and sharing household duties. However, the researchers also noted the limitations of examining changes in men's views of dominant norms of masculinity through self-reports without observing the men's actions once the workshops they attended had ended.

\section{Implications}

Given that participant's SRH practices were situated in the types and subjective meaning of their sexual relationships, HIV-prevention efforts should address hegemonic forms of masculinity according to different categories of relationships among both men and women. Since sex in established relationships was reportedly likely to be unprotected sex, equating intimacy and 'trust' to no need for condom use needs to be interrogated, particularly since this notion of trust was often determined relatively quickly, without knowing the other partner's HIV status. Rather than being promoted chiefly as a method of HIV-risk reduction, safer-sex practices could be promoted as an expression of mutual care, openness and love (Cusick and Rhodes 2000). Condom use was most frequently reported among couples in order to prevent pregnancy and they could be more heavily promoted as prevention against contraception, which does not conflict with notions of fidelity. Anxieties on behalf of men sexually satisfying their partners were common and could be a potential avenue to more actively involve men in SRH care. Interrogating men's and women's narratives and how they differ from hegemonic norms, such as instances of men who preferred sex with emotional intimacy and an acknowledgment of women's sexual desires, could be an effective tool to promote gender equitable relationships. When couples reported testing for HIV, it was often as a result of the encouragement of the woman - an entry point for HIV prevention that could be expanded. Nonetheless, since established relationships could be formed and change regularly, the timeframe for couples to be engaged by HIV interventions, including promotion of HIV testing, is limited.

The finding that most participants displayed knowledge and use of condoms in casual relationships is encouraging, yet alcohol consumption was cited as regularly impeding on 
their use. Given that South Africa has one of the highest rates of alcohol abuse in the world, programmes that seek to reduce unhealthy alcohol consumption, educate people about the associated SRH risks and interrogate the relationship between masculinity and alcohol use are warranted (Peacock and Barker 2012). Many of the women discussed their agency to insist on condom use, yet this may also reflect the neglect of men to initiate contraception. Initiating condom use could be promoted as a sign of men's sexual knowledge and confidence, but this must be done in congruence with encouraging men to have dialogue for joint responsibility with their partners around sexual decision-making (Waldby, Kippax, and Crawford 1993). Many women discussed their engagement in casual relationships for financial reasons, which is problematic given research suggesting that women are more likely to acquire HIV in a transactional relationship, where men hold greater decision-making power (Shefer, Cloves, and Vergnani 2012; Jewkes et al. 2012b). Thus, the economic empowerment of women, and addressing gendered norms around transactional sex, are critical for effective HIV-prevention efforts.

The reported common occurrence of multiple concurrent partners revealed through the narratives is worrying given research suggesting that high rates of concurrency contribute to HIV prevalence in South Africa, although there is lack of consensus on this finding (Parker et al. 2007; Lurie and Rosenthal 2010). The narratives indicated that condom use tends to be lower among main partners in long-term concurrent relationships, as suggested in other studies (cf. Epstein and Morris 2011). A promising finding is that many participants spoke of the necessity of practicing safer-sex with their side partner(s) to prevent a risk of HIV transmission to their main partner - this could also be drawn upon more effectively in HIV-prevention efforts. However, most participants reported hiding their side partner(s) from their main partner, which kept them uninformed of potential SRH risks. Sexual and/or emotional dissatisfaction of a partner was given as a major reason for engaging in concurrent partnerships. This finding highlights the need for interventions to equip couples to have honest discussions about their sexual and emotional desires and expectations. Many participants indicated that women more or less tolerate men's engagement with multiple partners, which highlights that partnering-reduction programmes will best succeed if they target both men and women's normative expectations and ideals of men (Leclerc-Madlala 2009). Hegemonic norms that link concurrency and masculinity must also be addressed by HIV-prevention efforts (LeclercMadlala 2009; Mah and Maughan-Brown 2013).

\section{Acknowledgements}

We are grateful to the participants for sharing their stories with us. Funding was received from USAID, Johns Hopkins Health and Education South Africa Die Deutsche Gesellschaft für Internationale Zusammenarbeit $\mathrm{GmbH}$ and the University of Cape Town Research Associateship. We thank the Centre of AIDS Development, Research and Evaluation for facilitating the initial phase of the study.

\section{Notes}

1. The first author, a white Canadian woman, may have been deemed an outsider by the participants, which may have limited participants' openness. However, at the time of the interviews, the author had spent a few years in South Africa as a researcher engaged in gender and HIV issues. Furthermore, participants may be more open with a 'foreign' individual, perceiving them as offering a safe space, or because concepts inherent to cultural understanding need to be explained more, which can lend to richer data regarding social norms. Nonetheless, interviewer bias and participant bias is a limitation of the research. To minimise this, the first author aimed to be reflexive through confirming 
interpretations of the data with South African researchers, regular engagement with relevant social issues and ensuring sensitivity around cultural and social norms during interviews.

2. Khwapheni originates from the Nguni term used in siXhosa and isiZulu, iKwapha, which translates to armpit. Khwapheni is frequently used to suggest a sexual partner that would be hidden under the armpit.

\section{References}

Attride-Stirling, J. 2001. "Thematic Networks: An Analytic Tool for Qualitative Research." Qualitative Research 1 (3): 385-405.

Brod, H. 1994. "Some Thoughts on Some Histories of Some Masculinities: Jews and Other Others." In Theorizing Masculinities, edited by D. David, and R. Brannon. Thousand Oaks, CA: Sage.

Campbell, J., M. Baty, R. Ghandour, J. Stockman, L. Francisco, and J. Wagman. 2008. "The Intersection of Intimate Partner Violence against Women and HIV/AIDS: A Review." International Journal of Injury Control and Safety Promotion 15 (4): 221-231.

Campbell, C., and C. MacPhail. 2002. "Peer Education, Gender and the Development of Critical Consciousness: Participatory HIV Prevention by South African Youth." Social Science \& Medicine 55 (2): 331-345.

Campo-Engelstein, L. 2013. "Raging Hormones, Domestic Incompetence, and Contraceptive Indifference: Narratives Contributing to the Perception That Women Do Not Trust Men to Use Contraception." Culture, Health \& Sexuality 15 (3): 283-295.

Connell, R. 1995. Masculinities. Cambridge: Polity Press.

Connell, R. W., and J. Messerschmidt. 2005. "Hegemonic Masculinity: Rethinking the Concept." Gender and Society 19 (6): 829-859.

Corbett, M., J. Dickson-Gomez, H. Hilario, and M. Weeks. 2009. "“A little thing called love': Condom Use in High-risk Primary Heterosexual Relationships." Perspectives on Sexual and Reproductive Health 41 (4): 218-224.

Cornwall, A. 1997. "Men, Masculinity and Gender in Development." Gender and Development 5 (2): $8-13$.

Cusick, L., and T. Rhodes. 2000. "Sustaining Sexual Safety in Relationships: HIV Positive People and Their Sexual Partners." Culture, Health \& Sexuality 2 (4): 473-487.

Dwadwa-Henda, N., S. Mfecane, T. Phalane, K. Kelly, L. Myers, and H. Hajiyiannis. 2010. Social Mobilisation and Communication to Prevent Mother-to-Child Transmission of HIV. Johannesburg: Centre for AIDS Development Research and Evaluation (CADRE) \& UNICEF.

Dworkin, S., M. Dunbar, S. Krishnan, A. Hatcher, and S. Sawires. 2011. "Uncovering Tensions and Capitalizing on Synergies in HIV/AIDS and Antiviolence Programs." American Journal of Public Health 101 (6): 995-1003.

Dworkin, S. L., A. M. Hatcher, C. Colvin, and D. Peacock. 2013. "Impact of a Gendertransformative HIV and Antiviolence Program on Gender Ideologies and Masculinities in Two Rural, South African Communities." Men and Masculinities, 16 (2): 181-202.

Epstein, H., and M. Morris. 2011. "Concurrent Partners and HIV: An Inconvenient Truth." Journal of the International AIDS Society 14 (13): 1-8.

Frosh, S., A. Phoenix, and R. Pattman. 2002. Young Masculinities: Understanding Boys in Contemporary Society. New York: Palgrave.

Harrison, A. 2008. "Hidden Love: Sexual Ideologies and Relationship Ideals among Rural South African Adolescents in the Context of HIV/AIDS." Culture, Health \& Sexuality 10 (2): $175-189$.

Hearn, J. 2004. "From Hegemonic Masculinity to the Hegemony of Men." Feminist Theory 5 (1): $49-72$.

Hunter, M. 2005. "Cultural Politics and Masculinities: Multiple-partners in Historical Perspective in Kwazulu-Natal." Culture, Health \& Sexuality 7 (4): 389-403.

Jewkes, R., and R. Morrell. 2010. "Gender and Sexuality: Emerging Perspectives from the Heterosexual Epidemic in South Africa and Implications for HIV Risk and Prevention." Journal of the International AIDS Society 13: 6.

Jewkes, R., and R. Morrell. 2012. "Sexuality and the Limits of Agency among South African Teenage Women: Theorising Femininities and Their Connections to HIV Risk Practises." Social Science \& Medicine 74 (11): 1729-1737. 
Jewkes, R., K. Dunkle, M. Nduna, and N. J. Shai. 2012a. "Transactional Sex and HIV Incidence in a Cohort of Young Women in the Stepping Stones Trial." AIDS and Clinical Research 3 (5): 1-8.

Jewkes, R., R. Morrell, Y. Sikweyiya, K. Dunkle, L. Penn-Kekana, and B. J. Shea. 2012. "Men, Prostitution and the Provider Role: Understanding the Intersections of Economic Exchange, Sex, Crime and Violence in South Africa." Plos ONE 7 (7): e40821.

Leclerc-Madlala, S. 2009. "Cultural Scripts for Multiple and Concurrent Partnerships in Southern Africa: Why HIV Prevention Needs Anthropology.” Sexual Health 6 (2): 103-110.

Lurie, M., and S. Rosenthal. 2010. "Concurrent Partnerships as a Driver of the HIV Epidemic in SubSaharan Africa? The Evidence is Limited." AIDS and Behavior 14 (1): 17-24.

Mah, T., and B. Maughan-Brown. 2013. "Social and Cultural Contexts of Concurrency in a Township in Cape Town, South Africa." Culture, Health \& Sexuality 15 (2): 135-147.

Mfecane, S. 2013. "Can Women 'Refuse' Condoms? Dilemmas of Condom Negotiation among Men Living with HIV in South Africa." Culture, Health \& Sexuality 15 (3): 269-282.

Morrell, R., R. Jewkes, and G. Lindegger. 2012. "Hegemonic Masculinity/Masculinities in South Africa: Culture, Power, and Gender Politics." Men and Masculinities 15 (1): 11-30.

O'Sullivan, L. F., A. Harrison, R. Morrell, A. Monroe-Wise, and M. Kubeka. 2006. "Gender Dynamics in the Primary Sexual Relationships of Young Rural South African Women and Men." Culture, Health \& Sexuality 8 (2): 99-113.

Parker, W., M. Makhubele, P. Ntlabati, and C. Connolly. 2007. Concurrent Sexual Partnerships amongst Young Adults in South Africa: Challenges for HIV-prevention Communication. Johannesburg: Centre for AIDS Development, Research and Evaluation (CADRE).

Peacock, D., and G. Barker. 2012. "Working with Men and Boys to Advance Gender Equality." Paper presented at UN Women expert group meeting prevention of violence against women and girls, Bangkok, Thailand.

Peacock, D., L. Stemple, J. Sawires, S. Sharif, and T. Coates. 2009. "Men, HIV/AIDS, and Human Rights." JAIDS Journal of Acquired Immune Deficiency Syndromes 51 (Suppl. 3): S119-S125.

Pettifor, A., C. MacPhail, A. Anderson, and S. Maman. 2013. "If I buy the Kellogg's Then He Should [Buy] the Milk': Young Women's Perspectives on Relationship Dynamics, Gender Power and HIV Risk in Johannesburg, South Africa." Culture, Health \& Sexuality 14 (5): 447-490.

Pettifor, A., H. Rees, I. Kleinschmidt, A. Steffenson, C. MacPhail, L. Hlongwa-Madikizela, K. Vermaak, and N. Padian. 2005. "Young People's Sexual Health in South Africa: HIV Prevalence and Sexual Behaviors from a Nationally Representative Household Survey." AIDS 19 (14): $1525-1534$.

Reddy, S., and M. Dunne. 2007. "Risking It: Young Heterosexual Femininities in South African Context of HIV/AIDS." Sexualities 10 (2): 159-172.

Robins, S. 2008. From Revolution to Rights in South Africa: Social Movements, NGOs and Popular Politics. Pietermaritzburg: University of KwaZulu-Natal Press.

Schneider, V., K. Cockcroft, and D. Hook. 2008. "The Fallible Phallus: A Discourse Analysis of Male Sexuality in a South African Men's Interest Magazine." South African Journal of Psychology 38 (1): 136-151.

Shefer, T., L. Cloves, and T. Vergnani. 2012. "Narratives of Transactional Sex on a University Campus." Culture, Health \& Sexuality 14 (4): 435-447.

Shefer, T., and D. Foster. 2009. "Heterosex among Young South Africans: Research Reflections." In The Prize and the Price Stein: Shaping Sexualities in South Africa, edited by M. Stein, and M. van Zyl, 267-289. Cape Town: HSRC Press.

Shefer, T., K. Ratele, A. Strebel, N. Shabalala, and R. Buikema. 2007. From Boys to Men: Social Constructions of Masculinity in Contemporary Society. Lansdowne: UCT Press.

Susser, I., and Z. Stein. 2000. "Culture, Sexuality and Women's Agency in the Prevention of HIV/AIDS in Southern Africa." Public Health Matters 90 (7): 1042-1047.

Talbot, K., and M. Quayle. 2012. "The Perils of Being a Nice Guy: Contextual Variation in Five Young Women's Constructions of Acceptable Hegemonic and Alternative Masculinities." Men and Masculinities 13 (2): 225-278.

Waldby, C., S. Kippax, and J. Crawford. 1993. "Cordon Santaire: 'Clean' and 'unclean' Women in the AIDS Discourse of Young Men." In AIDS: Facing the Second Decade, edited by P. Aggleton, P. Davies, and G. Hart, 29-40. London: Falmer Press. 
Wood, K., and R. Jewkes. 2001. "Dangerous Love: Reflections on Violence among Xhosa Township Youth." In Changing Men in Southern Africa, edited by R. Morrell, 317-336. Pietermaritzburg: University of Natal Press.

Wood, K., and R. Jewkes. 2006. "Blood Blockages and Scolding Nurses: Barriers to Adolescent Contraceptive Use in South Africa." Reproductive Health Matters 14 (27): 109-118.

\section{Résumé}

En Afrique du Sud, le positionnement fréquent des comportements sexuels des hommes comme vecteur principal de l'épidémie de VIH a généré beaucoup d'intérêt pour la sexualité des hommes. Cependant la nature relationnelle des normes masculines dominantes qui augmentent le risque de transmission du VIH est mal comprise. Cette étude s'est basée sur des biographies sexuelles pour examiner comment les hommes et les femmes négocient les normes de genre et comment cela affecte leur santé sexuelle et reproductive. 50 entretiens sur les histoires sexuelles individuelles et 10 groupes de discussion thématique ont été conduits avec des hommes; et 25 entretiens sur les histoires sexuelles individuelles ont été conduits avec des femmes, les participant(e)s ayant été échantillonné(e)s dans trois tranches d'âge (18-24 ans, 25-55 ans, 55 ans et plus), dans une gamme d'origines culturelles et ethniques et dans des sites urbains et ruraux à travers cinq provinces de l'Afrique du Sud. Les récits qui ont été collectés montrent que la santé sexuelle et reproductive des hommes et des femmes dépend largement du type et de la qualité des relations de chacun. La sexualité des hommes a été régulièrement décrite comme détachée de l'intimité et incontrôlable, ce qui était considéré comme étant à l'opposé de la sexualité des femmes et/ou supérieur à celle-ci, et pouvait justifier les comportements sexuels à risque élevé chez les hommes. Pourtant de nombreux participants étaient également favorables aux relations équitables à l'égard des deux genres et approuvaient les masculinités et les féminités différentes. Les récits révèlent que les normes masculines dominantes associées au risque d'infection par le VIH doivent être abordées dans une optique relationnelle pour garantir les meilleurs résultats possibles en matière de santé sexuelle et reproductive.

\section{Resumen}

En Sudáfrica, los comportamientos sexuales de los hombres frecuentemente son caracterizados como el motivo principal de la epidemia de vih, por lo cual existe mucho interés en la sexualidad masculina. A pesar de ello, no existe una comprensión completa de la naturaleza relacional vinculada a las normas masculinas que exacerban el riesgo de la transmisión de vih. Para analizar cómo los hombres y las mujeres se interrelacionan con las normas de género y cómo lo anterior afecta su salud sexual y reproductiva (ssr), el presente estudio se apoyó en biografías sexuales. Con este objetivo se llevaron a cabo 50 entrevistas de historia sexual, 10 diálogos de grupo focal con hombres y 25 entrevistas de historia sexual con mujeres. Los participantes seleccionados pertenecen a uno de tres grupos de edades -18-24 años, 25-55 años y más de 55 años-, tienen diversas procedencias culturales y raciales, y residen en ámbitos urbanos y rurales de cinco provincias de Sudáfrica. Sus narrativas dan cuenta de que tanto la ssr de los hombres como la de las mujeres depende principalmente del tipo y de la calidad de la relación que establezcan. Es común que la sexualidad de los hombres sea caracterizada como distante de la intimidad e incontrolable, vista como contraria y/o superior a la de las mujeres, lo cual puede justificar los comportamientos de alto riesgo de los mismos. Sin embargo, muchos de los participantes apoyan la equidad de género en las relaciones, a la vez que respaldan las masculinidades y las feminidades alternativas. Estas narrativas demuestran que las normas masculinas dominantes, riesgosas por el peligro que conllevan de contraer el vih, deberán ser atendidas tomando en cuenta las relaciones, con el fin de lograr mejores resultados en términos de la ssr. 